\title{
Developing a school-based drug prevention program to overcome barriers to effective program implementation: The CLIMATE schools: Alcohol module
}

\author{
Laura E. Vogl ${ }^{1}$, Maree Teesson ${ }^{1}$, Nicola C. Newton ${ }^{1 *}$, Gavin Andrews ${ }^{2}$ \\ ${ }^{1}$ National Drug and Alcohol Research Centre, University of New South Wales, Sydney, Australia; ${ }^{*}$ Corresponding Author: \\ nickien@unsw.edu.au \\ ${ }^{2}$ Clinical Research Unit for Anxiety and Depression, University of New South Wales, Sydney, Australia
}

Received 1 March 2012; revised 16 April 2012; accepted 20 May 2012

\section{ABSTRACT}

Although effective school-based alcohol prevention programs do exist, the overall efficacy of these programs has been compromised by implementation failure. The CLIMATE Schools: Alcohol Module was developed to overcome some of the obstacles to high fidelity program implementation. This paper details this development of the CLIMATE Schools: Alcohol Module. The development involved two stages, both of which were considered essential. The first stage, involved reviewing the literature to ensure the program was based on the most effecttive pedagogy and health promotion practice and the second stage involved collaborating with teachers, students and specialists in the area of alcohol and other drugs, to ensure these goals were realised. The final CLIMATE Schools: Alcohol Module consists of computer-driven harm minimisation program which is based on a social influence approach. The program consists of six lessons, each with two components. The first component involves students completing an interactive computer-based program, with the second consisting of a variety of individual, small group and class-based activities. This program was developed to provide an innovative new platform for the delivery of drug education and has proven to be both feasible and effective in the school environment. The success of this program is considered to be testament to this collaborative development approach.

Keywords: Program Development; Implementation; School-Based; Drug Prevention; Alcohol

\section{INTRODUCTION}

Early initiation to drug use is associated with a range of negative consequences including substance use disorders, mental health problems, juvenile offending, impaired educational performance and early school dropout, resulting in negative impacts on both current functioning and future life options [1,2]. School-based prevention programs are ideally placed to access young people before significant drug use problems develop [3]. School-based programs shown to be most effective in preventing drug-related problems have their content based on a social influence approach and are delivered in an interactive manner [4]. Despite these programs having demonstrated small effects in modifying drug use [5-7], the effectiveness of such programs is often compromised by implementation failure [8].

This poor implementation is evidenced by a review of United States (US) schools which showed that although almost two-thirds of teachers reported implementing effective content; only $17 \%$ provided an interactive delivery style. Of great concern, was that only $14 \%$ used both effective content and delivery [9]. These findings are consistent with a number of further studies which have shown that the number of teachers who implement programs with high fidelity to be low [10-12]. Although very few studies have examined the relationship between implementation and outcome, not surprisingly there is a strong relationship between the quality of implementation and the strength of program outcome [8,13-16]. These studies clearly demonstrate that implementation failure can compromise the efficacy of school-based prevention programs, making it essential to identify the factors that impede effective implementation $[12,17,18]$.

A number of factors impede the effective implementation of prevention programs. Poor teaching training $[8,14$, $19,20]$ is one factor which results from the difficulty of 
releasing teachers in an environment with such scarce resources [9]. The majority of programs require between 1 - 3 days of training [12,18,21-25]. Many teachers are also not fully informed or comfortable with using interactive techniques which are essential for program efficacy $[15,19]$.

Time constraints and competing demands on educational hours also mean that complex and lengthy programs are unlikely to be completely implemented $[8,10$, 26]. Evaluated program vary from 15 to over 100 sessions $[11,12,18,24,25,27,28]$, all of which may be too long in a pressured environment [29]. This reality contrasts with the evidence that the more intensive programs are more effective [4,5]. It is also the longer more intensive programs that are adapted or will fail to be implemented at all [26]. Program adaptation is one of the biggest threats to implementation fidelity [16], as most programs do not specify which program components are essential and non-essential [14]. In the US, adaptation is widespread with nearly $80 \%$ of teachers reporting program adaption [16].

For teachers, to prevent programs from becoming an extra task, they need to be curriculum-based and provide measures of educational outcomes [8,19]. Likewise, programs that are packaged simply, have clear instructions and are easy to administer are more likely to be implemented and implemented with greater fidelity $[8,13,30]$. Fidelity may also be enhanced if manuals can clearly specify the essential and non-essential components [14].

The aim of the current research was to develop an innovative new platform for the delivery of prevention education in schools which would help to overcome the barriers to implementation. Prevention programs delivered utilising computer technology have such potential. Computer technology has advantages over more traditional means of delivering prevention programs; namely, the computer has the control of both the content and delivery of the program and can provide complete, consistent and interactive delivery on every occasion. Welldesigned computer programs guarantee simplicity and ease of use. The use of computer technology in comparison to more traditional teaching techniques has been shown to accelerate learning; potentially enabling programs to be shorter [31]. Importantly they provide the capacity of going to scale without compromising fidelity.

Computer-based drug prevention programs do exist. They generally involve young people navigating through simulated real life situations involving characters to which they can relate. These programs have demonstrated the capacity to increase knowledge [32] and drug resistance skills [33], decrease pro-drug attitudes [34] and intention to use drugs [33]. However, evaluations of computer-based school alcohol prevention programs are limited by the use of single session programs which are not fully integrated into the curriculum [33,34]. The aim of the current article is to outline the development of a computer-based school alcohol prevention program which was fully integrated into the curriculum, involved multiple sessions and has been shown in two randomised controlled trials to be effective in improving knowledge and attitudes, and importantly decreasing alcohol misuse $[35,36]$.

The development of the CLIMATE Schools: Alcohol Module (CLIMATE) involved two stages, both of which were considered essential. The first stage, involved reviewing the literature to ensure the program was based on the most effective pedagogy and health promotion practice [37]. The second stage involved collaborating with teachers, students and specialists in the area of alcohol and other drugs, to ensure these goals were realised. Collaboration with teachers is considered to be an essential step for ensuring that programs can easily be implemented into the school setting [38]. The current paper outlines the different stages of this collaborative development process.

\section{METHODS \& RESULTS}

\subsection{Stage 1-Reviewing the Literature}

In developing CLIMATE, three factors were important 1) the focus, goals and timing of the intervention, 2) the content of the intervention, and 3) the delivery of the intervention.

The focus, goals and timing of the intervention: The focus of a school-based drug prevention program must be relevant and developmentally appropriate [20,39]. As alcohol is the substance most frequently used by adolescents [40] it was relevant and appropriate as the drug of focus.

Interventions must also have clear goals. The failure of many alcohol prevention programs to achieve significant behavioural changes has been attributed to the lack of clearly specified program goals leading to the delivery of inconsistent and ambiguous messages [41]. Program goals need to be culturally appropriate and address local needs, values and priorities [39,42] The overarching goals of the program also need to be consistent with that of the host community [30]. Developing a prevention program based on a harm minimisation approach in Australia was the appropriate goal, as it is in line with the Australian National Drug Strategy [43]. The goal of this strategy is to prevent and minimise alcohol related harms to individuals, families and communities in the context of developing safer and healthy drinking cultures in Australia. This is an approach that is accepted by both teachers and students in Australian schools [44].

The specific goals of an intervention also depend on the timing of the intervention. The best timing for the 
prevention of alcohol misuse is the early relevance phase when most students are experiencing initial exposure. Delivering an intervention at this time ensures that students gain exposure to programs when information and skills are most likely to have meaning and practical application, prior to the establishment of harmful patterns of consumption [45].

Content of the program: School-based programs based on the social influence approach to drug prevention have been shown to be the most effective drug prevention programs (6). These programs contain three essential components; information, normative component and resistance skills training. The exact nature of these components varies under a harm minimisation approach compared with an abstinence based model [20,46].

Information: The information provided needs to be immediately relevant and developmentally appropriate. It must be based on here and now outcomes and not outcomes which may occur in the distant future [20,47]. The information provided needs to be accurate, relevant and credible to young people [48]. It needs to discuss the positive and negative aspects of drug use and dispel any myths that may exist [37]. In a harm minimisation program, the information provided should assist in reducing the immediate legal, social, psychological and physical consequences of alcohol consumption [46]. The ultimate harm minimisation message is that all such harms can be avoided if young people choose not to drink alcohol [49]. However, for those who do choose to drink alcohol, guidelines need to be provided to help young people to minimise the risk of alcohol related harms. In Australia, the Australian National Health and Medical Research Council publish the Australian alcohol guidelines [50], which at the time of program development were the 2001 guidelines [51] which have since been superseded by the 2009 guidelines.

Normative component: The focus of the normative component is extremely important and used to reinforce that the prevalence of risky use among young people is not high. The normative component demonstrates that even if adolescents choose to use alcohol that the majority choose to use it in a way which is low in risk and less harmful. That is, the aim of the normative component is to legitimise safer choices [37].

Resistance skills: Consistent with a harm minimisation framework, the resistance skills component teaches skills to resist or minimise harms [46]. It teaches young people the skills to identify the pressures to consume alcohol that may be exerted from peers, family, media and society. This involves teaching skills to resist alcohol offers, in addition to skills to recognise the contextual risks associated with when, where, and with whom they choose to consume alcohol or other drugs [37]. The aim is to teach young people to resist such pressures whilst main- taining friendships and social standing [20]. This approach has resulted in behavioural effects which are equal to or greater than the resistance skills training alone [46] and was incorporated in the current program.

Delivery: Delivering school-based drug prevention programs as part of a broader school health curriculum is essential as it enables young people to see the link between broader social and health skills and allows teachers to see how the information fits with other instructional topics [39,42]. The program content should be mandated by curriculum guidelines and consequently can no longer be viewed as an extra task [52]. Broader based drug education programs have also been found to be more effective than stand alone and one-off programs [42].

For school-based drug prevention programs to be effective, it is vital that all three essential components of the program are delivered (i.e., information, normative and resistance skills) and that the delivery is interactive [52]. Effective learning also requires that young people have the opportunity to personally interact with the material in a meaningful way which is relevant to their own lives [37]. Computer technology is an age appropriate tool which can be utilised to simulate real life situations involving characters and contexts to which young people can relate [53,54], which allows for this level of interacttion.

Computer technology can potentially guarantee complete delivery of the content in each lesson, but cannot guarantee that teachers would deliver "all” lessons. The use of a computer-based teenage drama to impart the information and skills is a possible solution to circumvent this issue. Specifically, this would mean that the lessons would form "consecutive episodes", which would encourage teachers to deliver the information in the right order and in their entirety, or risk not satisfying student's curiosity about what the outcome may be in the next episode of the teenage drama.

Varying recommendations exist regarding the length of effective school-based drug prevention programs [5,6, 45,52]. The majority suggest that the more intensive programs are the more effective programs (i.e., 11 - 30 hours in length) $[5,6,45]$, but without careful monitoring these are the programs that fail to be delivered correctly and in the entirety. Given that the aim of developing this program was to overcome obstacles to implementation and computer technology has been shown to accelerate the rate of learning, the current intervention would be designed to be brief.

In summary, the review of the literature suggested the program would be a brief computer-driven harm minimisation program based on a social-influence approach. The program would be integrated into the school health curriculum and clearly linked to required curriculum outcomes. It would be delivered to students at approxi- 
mately 13 years of age (Year 8 of high school) as according to large scale Australian epidemiological surveys this is the time when the majority of young people are first experimenting with alcohol, but prior to the establishment of harmful patterns of consumption [55]. Hence, the next stage of the development process involved developing scripts for the teenage drama and then conducting focus groups/interviews with teachers, students and specialists in the area of alcohol and other drugs to determine the accuracy, feasibility and acceptability of this proposed innovative new model for drug prevention in the school setting.

\subsection{Stage 2-Creating the Initial Program/Scripts and Conducting Focus Groups with Key Stakeholders}

The initial scripts for the CLIMATE Schools: Alcohol Module were eight lessons in length, with each lesson forming part of an ongoing cartoon-based teenage drama which followed the lives of five teenagers and their alcohol related exploits. Story lines provided by young people, teachers, parents and medical practitioners were used to inform the story-lines covered in the teenage drama.

\subsubsection{Key Informant Sample and Recruitment}

Twelve specialists in the area of drug and alcohol prevention and mental health prevention and treatment were recruited from two sites; the National Drug and Alcohol Research Centre (NDARC) and the Clinical Research Unit for Anxiety and Depression (CRufAD).

Twenty-three teachers (39\% male) from 12 schools in New South Wales were recruited at an area meeting of school health curriculum coordinators to assist with the development. Teachers ranged in age from 23 to 59 years of age (Median age 27). Teaching experience ranged from one to 35 years, with $43 \%$ having five or less years of teaching experience (Median 6 years). In the second set of focus groups, a further three teachers agreed to participate, one of which came from a different school to those involved in the first focus groups.

Seven young people (57\% male) between 10 to 16 years of age were recruited through staff at the NDARC and two were recruited through schools by participating teachers. Eight young people (50\% male) aged between 12 and 16 years participated in the second round of focus groups. Six of these students were in common to both sets of focus groups. Three police-officers with an interest in the prevention of alcohol misuse were approached and agreed to participate. Likewise, two general practitioners, known to research staff, also agreed to participate. Legal advice regarding the scripts was sought from the University of New South Wales lawyers.

\subsubsection{Procedure}

The development of the CLIMATE Schools: Alcohol Module involved an iterative process. Even prior to the formal review process, during the recruitment of key stakeholders, teachers immediately commented that it would not be possible to fit 8 lessons entirely devoted to alcohol into the Year 8 curriculum. Given that there was some evidence that harm minimisation programs could achieve significant positive behavioural effects with as few as four or five sessions [56,57] the program was condensed to 5 lessons prior to the first interview/focus groups.

Experts in the area of alcohol and other drugs/prevention, police and medical practitioners (specialists in AOD) were the first to be interviewed. The scripts were provided a week in advance and they were asked to provide feedback on the accuracy of the information and prevention message. Scripts were modified accordingly.

The second stage involved in-depth interviews with teachers. Since implementation in the school environment was the major focus in the current research, teachers were also asked to complete two surveys. Teachers were reimbursed $\$ 50$ for their time. Once all feedback had been received, where the feedback was unanimous across participants and consistent with evidence-based principals of drug education [42], the program was modified to reflect the feedback provided. Student interviews were less intensive and were conducted concurrently with teacher interviews. Students were asked what they thought of the program and whether they could relate to the storylines and language which was included. They were also asked whether they would like to learn material in this format and to make possible suggestions for alternative story-lines.

Once the scripts had again been revised, a second set of less formal focus groups/interviews were conducted with the same groups in the same order. On completion of the second set of focus groups, police and general practitioners were also interviewed to ensure the accuracy of the revised program content.

\subsubsection{Interview Analysis and Measures}

Interview and focus groups: a thematic analysis of the teacher and student interview/focus group material was performed by Dr Vogl. Additional comments from teacher surveys were also used in this analysis. This analysis was performed with the aid of Microsoft excel.

Surveys: Teacher survey 1: The teacher survey used in the first focus group was an 18 item survey which covered 5 domains: Demographics, program content, implementation, program effectiveness, curriculum compliance and the harm minimisation focus. 
Demographics: Years of teaching, age, gender, school type (Catholic, Independent) and school composition (single sex male, single sex female or coeducational).

Program Characteristics: For each of 6 questions, teachers were asked to indicate on a "yes/no" scale for each lesson whether or not the scripts were suitable on each of the following areas 1) script credibility (i.e., acceptability, believability and validity for students); 2) educational content (i.e., reasonable and appropriate); 3) learning (would students be able to understand and remember); 4) length (adequate to cover concepts being taught); 5) acceptability of language for students; and 6) acceptability of language and storyline for teachers/ schools. An average score across all lessons was computed for each area.

Implementation concerns: Teachers were asked 8 questions regarding possible barriers/benefits to implementation. For each question teachers were asked to indicate to indicate on a yes/no scale whether they thought the items would be a concern. The items included: 1) implementing in normal health curriculum; 2) any concerns with alcohol education being delivered by computer; 3) whether it was a practical way of teaching drug education; 4) whether teachers would need additional training in alcohol and other drug education; 5) sufficient time to set up the program; 6) sufficient computers for individual student terminals; 7) whether there was a school server to access the program from a common file; and 8) CDROM drive available.

Harm minimisation focus: Teachers were asked to indicate on a five-point likert scale from "extremely acceptable" to "not at all acceptable" whether or not they agreed with using a harm minimisation approach.

Perceived program effectiveness: Teachers were asked to rate on a five point likert scale from "extremely effecttive" to "not at all effective", how effective they thought the program would be in: 1) getting Year 8 students to either drink in moderation or not at all; and 2) getting Year 8 students to adopt strategies to reduce alcohol related harms in their lives.

Curriculum compliance: Teachers were asked to indicate on a five point likert scale from "extremely well” to "not at all well" how well they thought the program content fitted with the school health curriculum.

Teachers were given the option to provide any relevant comments on each domain for every lesson.

Teachers Survey 2: This survey included four items. These items asked teachers to rate on a likert scale 1) how well do you think Year 8 students would understand the concept/s being taught in this session? (very well, well, not very well, not at all); 2) do you think the scripts would be believable and socially valid to Year 8 students? (very believable and socially valid, moderately, a little, not at all); 3) do you think Year 8 students would under- stand all the language being used? (they would understand all the language, most of the language, half of the language, little of the language, and they would not understand the language at all); and 4) how much do you think Year 8 students would like the illustrations? (very much, moderately, a little, not at all).

\subsubsection{Feedback from the First Round of Focus Groups}

Specialist feedback: There was unanimous agreement that the scripts were correct in their content. All reviewers agreed that the scripts could be reviewed by teachers.

Teacher feedback: Table 1 provides a summary of the interview/focus group feedback under five different content domains. Table 2 provides mean responses to the different content domains in the teacher surveys. In summary, the teacher feedback suggested that a number of changes would need to be made to the overall program.

Student feedback: Student's reported they would enjoy learning from a resource of this nature. They, however, found some of the scenes unbelievable and difficult to relate to (e.g., a park brawl, the dinner with parents). They also reported that the section on alcohol advertising only used examples which were relevant to females. Although the students found the swearing and lewd remarks quite acceptable, they made numerous suggestions for alternative language which would be more appropriate for their age group. The students also provided a number of suggestions for alternative scenes.

\subsubsection{Program Changes from the First Round of Focus Groups}

Script changes: Based on teacher and student feedback, changes were made to the program content and implementation. The changes which were adopted were those which were consistent with evidence-based principles for effective drug education [39,42] and are outlined in Table 3. Recommendations which were not consistent with evidence-based principles for effective drug-education were not included and are addressed in the discussion. In re-writing the scripts, information was also sought from New South Wales Police, and school teachers to ensure scene portrayals/storylines were accurate.

Creating the teacher manual and student activities: One of the most substantial changes which came about was from the first round of focus groups was the need to create a program manual. Prior to developing the teacher's manual and student activities, a number of existing programs were reviewed. These programs included: 1) A Resilience Approach to Drug Education: REDI [58]; 2) Life Skills Training: Middle School Program [59]; 3) Project Towards No Drug Use [60]; 4) School Health and Alcohol Harm Reduction Project (SHAHRP): Teacher 
Table 1. Summary of teacher feedback from Round 1 focus groups/interviews.

\begin{tabular}{|c|c|}
\hline Areas of Strength & Areas of Concern \\
\hline \multicolumn{2}{|c|}{ Program characteristics } \\
\hline $\begin{array}{l}\text { Believable and acceptable with good educational content that } \\
\text { would facilitate student learning and literacy skills } \\
\text { Allows for self-paced learning }\end{array}$ & $\begin{array}{l}\text { Does not cater for variable lesson lengths. } \\
\text { Students will complete the lessons at different rates. } \\
\text { Overall too long/some content too condensed. } \\
\text { Content too old for age group, better placed one year higher. } \\
\text { Two scenes not realistic (i.e., announcement of the death of a child at } \\
\text { school, family dinner). } \\
\text { Extraneous content distracting to students (e.g., contraceptive pill) } \\
\text { The content on long-term harms too subtle and needed to be made more } \\
\text { explicit. } \\
\text { The inclusion of swearing as students wouldn't take program seriously and } \\
\text { teachers, school and parents do not want to appear to condone swearing. } \\
\text { Other minor language changes. } \\
\text { Police portrayed negatively and need to be seen as positive role models } \\
\text { who could genuinely assist in preventing underage drinking. }\end{array}$ \\
\hline
\end{tabular}

Curriculum compliance

A comprehensive, competence-based drug prevention program which fitted well with the school curriculum.

The use of computers had just been added to the outcomes required in the new syllabus and this program would provide an immediate resource.
Would need a document which clearly linked the program to specific curriculum outcomes to assist with the school education auditing process would be beneficial.

\section{Implementation}

A computer resource would appeal to young people and would facilitate learning.

The majority of teachers would not require any training, with the exception of a few who would need updated statistics on alcohol use in Australia.
A computer program could not be the sole means of delivering drug education and that the resource would need to be teacher-centred and include additional interactive activities. Teachers also believed that it was essential that this extra material allow students to apply this information to situations relevant to students' own lives.

Would need support material to extend and occupy gifted children.

Computer access not all have servers.

Individual student computers.

Ease of loading CD/program.

Use of the Australian Alcohol Guidelines which are designed for adults. Needs to be made clear that children had to drink less to remain at low risk levels.

The scripts were too permissive of drinking and had failed to communicate that underage drinking was illegal and abstinence was the preferred option.

Required more information on other alcohol related harms (e.g., sexually

Strongly supported the use of a harm minimisation approach and believed it was not too complicated for young people to learn. transmitted infections).

Teachers recognised that to provide information and skills about alcohol that the scripts needed to revolve around alcohol-related scenes. They noted, however, that the use of a large number of alcohol related scenes had negated the conservative norms component which is an essential component of effective drug prevention programs.

Story lines needed more positive role-models.

Percieved effectiveness

Teachers were tempered in their view of the effectiveness of the program

Program would be moderately effective for two reasons:

1) the abstinence message was not salient enough in the scripts,

2) recognition that achieving behaviour change in young people is challenging.

Manual and Student Workbooks [61], 5) Cannabis and Consequences [62] and Rethinking Drinking [63].

The aim with the current manual was to design a program manual which was clear, easy and simple to use. It was the intention that in the development of this manual, that lack of teacher training and time to prepare activities needed to be taken into account. Teachers had requested student lesson summaries and activities. In terms of 
Table 2. Summary of teachers’ survey feedback for round 1 of focus groups/interviews.

\begin{tabular}{|c|c|c|c|c|}
\hline & Mean & Std. dev & Possible range & $\mathbf{N}$ \\
\hline \multicolumn{5}{|l|}{ Program content ${ }^{*}$} \\
\hline Credibility & 0.93 & 0.14 & $0-1$ & 17 \\
\hline Educational content & 0.93 & 0.12 & $0-1$ & 17 \\
\hline Learning & 0.91 & 0.17 & $0-1$ & 17 \\
\hline Length & 0.80 & 0.34 & $0-1$ & 16 \\
\hline Language/storyline for teachers/school & 0.22 & 0.26 & $0-1$ & 12 \\
\hline Language for students & 0.70 & 0.38 & $0-1$ & 14 \\
\hline \multicolumn{5}{|l|}{ Program effectiveness $^{* *}$} \\
\hline Drink in moderation & 2.52 & 0.59 & $0-4$ & 23 \\
\hline Adopt strategies & 2.74 & 0.69 & $0-4$ & 23 \\
\hline \multicolumn{5}{|l|}{ Curriculum compliance $^{* * *}$} \\
\hline Fit with curriculum & 3.29 & 0.78 & $0-4$ & 21 \\
\hline \multicolumn{5}{|l|}{ Harm minimisation $^{* * * *}$} \\
\hline How acceptable & 3.35 & 0.71 & $0-4$ & 23 \\
\hline Implementation $^{*}$ & \%Yes & $\%$ No & \%Undecided & $\mathbf{N}$ \\
\hline Curriculum fit & 60 & 25 & 15 & 20 \\
\hline Concerns computer delivered & 18 & 68 & 14 & 22 \\
\hline Practical way to teach & 96 & 0 & 4 & 22 \\
\hline Training required & 23 & 73 & 4 & 22 \\
\hline Enough set up time & 63 & 0 & 37 & 19 \\
\hline Access to individual terminal & 25 & 50 & 25 & 20 \\
\hline School server available & 5 & 70 & 25 & 20 \\
\hline CD-ROM drive available & 90 & 0 & 10 & 19 \\
\hline
\end{tabular}

${ }^{*}$ coded yes/no; where Yes $=1 ;{ }^{* *}$ coded $0=$ Not at all effective to $4=$ extremely effective; ${ }^{* * * *}$ coded $0=$ Not at all well to $4=\mathrm{ex}-$ tremely well ${ }^{* * * *}$ coded $0=$ Not at all acceptable to $4=$ extremely acceptable.

training they had indicated that all that would be required was up-to-date statistics. To cater for these needs a program manual was developed which provided four essential components for each lesson. These component were a 1) brief teacher summary of all facts and statistics required for the lesson which would take no longer than five minutes to read; 2) student lesson summary and notes; 3) range of fully prepared lesson activities to cater for different time intervals and classroom needs. As requested, a program outline was also provided to clearly delineate the fit of lessons to the Health curriculum. The revised scripts, program manual and preliminary cartoons for the teenage drama were then subject to the second round of focus groups/in-depth interview.

\subsubsection{Feedback from the Second Round of Focus Groups}

Specialist feedback: There was unanimous agreement that the scripts and manual were correct in their content and that the cartoons were appropriate.

Teacher feedback: Teachers' thought the revisions which had been made to the program had greatly improved the quality of the program. What was clear from the teacher feedback is that there was no longer one voice or clear themes that were being raised by teachers. All the teachers believed the CLIMATE Schools: Alcohol Module to be a good program and had minor suggestions for change. One hundred percent of teachers endorsed that the concepts being taught would be either "well" or "very well" understood. In terms of developmental appropriateness and Year 8 students' capacity to relate to the scripts, $68 \%$ of teachers rated the scripts to be very believable and socially valid. The remaining $32 \%$ rated them as moderately believable. In terms of the language, 92\% of teachers endorsed that "most" or "all" the language would be understood by students. Teachers 
Table 3. Changes to program resulting from teacher and student feedback.

Changes made to program content and delivery based on teacher feedback

\section{Major program changes:}

- A program manual with teacher and student summaries, an array of prepared classroom activities and clear links to curriculum outcomes would be included. The activities include role plays, small group discussions, decision making and problem solving activities and skill rehearsal, all of which have been identified as being central to program efficacy $(4,6)$.

- Comic books created for teachers who could not access computer facilities for consecutive lessons.

- The focus of the program continues to be one of harm minimisation, but the emphasis would be more strongly placed on 1) not drinking, 2) not drinking alcohol to get drunk, and 3) not drinking in unsupervised environments. This would also involve the inclusion of more positive role models and alternative alcohol-free activities. It would also be made clear that the Australian alcohol guidelines were for adults and for young people to drink at low-risk levels they either should not drink or drink less.

- The advertising section was modified to ensure that it was equally relevant to both males and females.

- The length of the program would be increased to 6 lessons to ensure that none of the essential content components were too condensed for effective learning.

Minor program changes:

- The section on long-term harms was broadened and made more explicit.

- Storylines which seemed trite (e.g., scene with parents in a restaurant, drunken brawl) or were inaccurately portrayed (e.g., school community being informed of a child's death), were either removed or modified to ensure that they were realistic and correctly portrayed. New scenes suggested by students were incorporated.

- Distracting unnecessary content was removed (e.g., reference to contraceptive pill).

- Police were presented in a more positive light.

- Swearing and lewd remarks were removed and replaced with street-wise, but acceptable language which had been provided by students. Care was taken to ensure that the street-wise language adopted would not easily date the program.

liked the cartoon illustrations. Eighty-eight percent indicated that Year 8 students would "very much" like the illustrations. The remaining $12 \%$ rated that students would "moderately" like them. The manual was rated very positively by all teachers and was seen as an excellent resource. Teachers provided extra activity ideas and recommended that illustrating the student summaries would increase the appeal.

Student feedback: In general, young people liked the cartoons and storyline. They reported that they thought young people would enjoy learning material in this format. They made minor modifications to the language.

Feedback from University lawyers, police and medical practitioners: University lawyers indicated that all product brand names had to be removed from the script. The two general practitioners who reviewed the scripts agreed the information provided on how to cope with an alcohol related medical emergency was accurate. Finally, a police officer from the NSW licensing police confirmed that the legal information provided in the scripts was correct.

\subsubsection{Program Changes from the Second Round of Focus Groups}

Teacher and student feedback led to minor changes in the program which included 1) a clearer program and curriculum outline; 2) a number of additional classroom activities; 3) the inclusion of illustrations and designs to make the student summaries and worksheets more interesting; 4) minor changes to language; and 5) the removal of all product names from the scripts.

A brief summary of the content of each lesson in the CLIMATE Schools: Alcohol Module is provided in Table 4 .

Table 4. Lesson content of CLIMATE schools: Alcohol Module.

\begin{tabular}{|c|c|}
\hline Lesson & Content \\
\hline 1 & $\begin{array}{l}\text { Alcohol, the law and underage drinking } \\
\text { Standard drinks } \\
\text { Australian alcohol guidelines for low risk drinking } \\
\text { Identifying the number of drinks in alcohol beverages } \\
\text { Societal pressures and expectations to drink }\end{array}$ \\
\hline 2 & $\begin{array}{l}\text { Prevalence and patterns of alcohol consumption among } \\
14 \text { - } 15 \text { year olds } \\
\text { Alcohol-free social activities } \\
\text { Identifying sources of pressure to drink too much alcohol } \\
\text { Identifying the reasons teenagers choose to or not to drink } \\
\text { alcohol } \\
\text { Dispelling myths about alcohol }\end{array}$ \\
\hline 3 & $\begin{array}{l}\text { Short- and long-term consequences of drinking too much } \\
\text { alcohol } \\
\text { Identifying the potential for risk and harm in common } \\
\text { teenage drinking scenarios } \\
\text { Exploring ways to prevent alcohol related harm in } \\
\text { common teenage drinking scenarios } \\
\text { Identifying sources of help for teenagers }\end{array}$ \\
\hline 4 & $\begin{array}{l}\text { Myths and facts about alcohol } \\
\text { Advertising tactics } \\
\text { Alcohol advertising laws } \\
\text { Alcohol advertising and youth }\end{array}$ \\
\hline 5 & $\begin{array}{l}\text { Alcohol refusal skills } \\
\text { Ways to minimise alcohol consumption } \\
\text { Tips to keep people safe who are drinking too much } \\
\text { alcohol } \\
\text { Decision-making about whether to consume alcohol and } \\
\text { the purpose of getting drunk } \\
\text { Examining different views on the consumption of alcohol }\end{array}$ \\
\hline 6 & $\begin{array}{l}\text { Ways to prevent an alcohol related medical emergency } \\
\text { Recognising the signs of an alcohol related medical } \\
\text { emergency } \\
\text { What to do if there is a medical emergency } \\
\text { Who to contact if there is a medical emergency } \\
\text { Calling the emergency number "000" } \\
\text { The recovery position }\end{array}$ \\
\hline
\end{tabular}




\section{DISCUSSION}

The aim of the current paper was to outline the development of the CLIMATE Schools: Alcohol Module, which is a computer-driven, school-based alcohol prevention program founded on a harm minimisation approach. Consistent with the evidence-based literature on best practice the CLIMATE Schools: Alcohol Module is based on a social influence approach and has been designed to be implemented in Year 8 of Australian high school (13 years of age), just prior to when a significant number of young Australians consume their first full glass of alcohol [64]. This corresponds to the early relevance phase, which is a time identified to have the greatest impact on drug use behaviour as it ensures that students gain exposure to programs when information and skills are likely to have the greatest meaning and practical application [45]. In line with recommendation from guidelines on developing effective school-based programs, this program was developed in collaboration with teachers, students and relevant health and legal professsionals [38]. This collaborative process helped to identify many recommendations for change in both the content and delivery of this program. It is these recommendations, if gone unnoticed that could have potentially become barriers to the high fidelity implementation, which may have presented this program from demonstrating such positive prevention outcomes $[35,36]$.

Consistent with past research conducted in Australia (for review see reference 44) and the Australian National Drug Strategy, teachers strongly supported the program being founded on a harm minimisation approach. Although teachers embraced this approach, they believed that earlier versions of the program were too permissive and gave the impression that all young people consume alcohol. Teachers reported that although they recognised it was essential to utilize alcohol-related scenarios to provide harm minimisation skills the use of too many of these scenarios had inadvertently made underage drinking appear prevalent and this had undermined the normative component of the program which was included in the scripts; a component that many would argue is essential to the success of a drug prevention program [65].

Based on teacher recommendations from their first review of the scripts, the content of this program was substantially changed to include positive non-drinking rolemodels and alcohol-free activities. It was clearly emphasised that the Australian Alcohol Guidelines were for adults and optimally young people should drink considerably less, with the ideal option being not at all. Hence the collaboration with teachers led to the creation of a harm minimisation message which was suitable with the school community.

Teachers' embraced the use of computer technology as they believed it would appeal to young people and facilitate learning. They did, however, believe that the resource could not be computer-based alone. Rather, they believed the lessons should have teacher-centred activeties and allow students to interact with peers and interact with the material in a meaningful and personally relevant way. As the suggestions from teachers echoed the recommendations of the evidence-based literature, a program manual was created with numerous interactive classroom, small group and individual activities. All of the above have been shown to be ingredients of effective school-based programs $[4,6]$. For each lesson the manual provided a teacher and student summary and a variety of readymade activities to ensure limited teacher preparation. Hence, in the final program each lesson consisted of two components. The first component involves students spending 20 - 25 minutes completing the interactive computer based program, with the remainder of the lesson being devoted to interactive individual, small group and class-based activities. The inclusion of this manual had a number of other advantages. The teacher summaries further decreased the need for teacher training. Specifically, only $23 \%$ of teachers believed that teachers would need extra training and all they believed they would require were updated statistics. This could easily be accommodated in the teacher summary. The large variety of readymade activities that required minimal, if any preparation should help to decrease the need for program adaptation. Importantly, the lesson-by-lesson clear links to the school curriculum also allowed teachers to easily determine if students had met educational outcomes and clearly delineated how the program fitted with other health topics and key learning areas.

Teachers welcomed the use of a computer tool. This was especially the case given that an information and computing technology component had been added into the NSW state health curriculum which was being introduced into schools. As this new curriculum, however, had not yet been fully transitioned into schools, teachers anticipated difficulty in gaining access to computers for six consecutive lessons. Hence, to smooth this transition, cartoon book back-up resources were provided to create a pragmatic solution. Initially, this led to some concern that this may decrease program interactivity, but with the inclusion of interactive class-based activities, this was considered to be less serious. The lack of individual terminals was not considered to be a problem as a past study found that a lack of available computers facilitated discussion between groups of students whilst they shared the computer which improved the overall interactivity of the program [32].

Teachers and students substantially modified the content and language of the initial scripts. Whilst maintaining the evidence-based content this helped to ensure that 
1) the content was accurate, balanced and believable; 2) young people could relate to the script; 3) no content was included which could potentially distract young people's attention from the topic at hand; and 4) most importantly, teachers felt comfortable delivering the content in the school environment.

The collaborative development of the CLIMATE Schools: Alcohol Module has led to a number of significant changes. This, however, did not mean that all recommendations were uncritically taken on board. A substantial number of teachers believed the content was more appropriate for Year 9 students (14 - 15 years old). They reported that although Year 8 students would be able to relate to the material, it was Year 9 students that would be participating in the activities covered in the scripts. Given that it is essential that prevention messages are immediately relevant but are conveyed just prior to the initiation of alcohol use and the establishment of harmful patterns, teachers' comments confirmed that this program was suitably placed in Year 8 of high school [39, 42,46].

Teachers are required to cover large quantities of information in the school curriculum, where the emphasis is on educational outcomes. As a result, many teachers requested an even shorter program than six lessons. This was not accommodated as it was at odds with the evidence, which clearly indicates that even longer more intensive programs are usually more effective in leading to behaviour change [5,6]. In addition, the removal of any of the content would not have been supported by the literature and condensing it further would not have facilitated learning. This conflict will continue to occur until the emphasis in school is on behaviour, rather than knowledge change [66].

Although the collaborative process assisted in creating a program which would be more acceptable and easily implemented in the school environment there were a number of limitations which could be addressed in future program development research. There were two stages of teacher and student reviews, both of which largely involved the same teachers and students. Ideally, the second stage of reviews should have involved a different sample, who may have made even further suggestions, rather than the use of the same sample who were largely satisfied as their suggestions had been taken on board. The teachers and students who participated were also self-selected, suggesting they had a greater interest in school-based alcohol prevention. Self-selection also suggests that that these teachers may have been more proactive in their desire to develop effective school-based resources and, as such, were a potentially more knowledgeable group. Having a less-motivated and knowledgeable group may have further highlighted important obstacles to high-fidelity implementation and may have indicated a higher level of need for teacher training.

A further limitation regards the fact that students and teachers were recruited from Independent and Catholic schools only. This was due to ethics approval only being sought from the University of New South Wales and not the Department of Education and training due to time constraints. In future, program developers may wish to obtain approval from the public education system and run focus groups with students and teachers from public schools as well.

However, even given these limitations, when the CLIMATE Schools: Alcohol Module was trialed in a cluster randomised controlled trial (RCT) involving 16 schools, 1434 students and 20 classroom teachers [36], ninety percent of teachers reported finding the program easy to implement and those that implemented the program were satisfied that it met the educational outcomes detailed in the new health curriculum. It was also clear that developing the program manual with teachers was effective, as it helped to build in likely teacher adaptations to the program [16]. This was evidenced by teachers' compliance with the program. Specifically, all teachers reported delivering all the lesson and using the activities in the program manual for $98 \%$ of the lessons which were delivered. The collaboration with teachers ensured that the program folder was simple to use, provided adequate variety of learning and minimal teacher preparation time. Teachers' recognition of this is evidence by the fact that on completion of the RCT, $100 \%$ of teachers reported that they would recommend the program to others and that they personally would be likely to use the program in the future. Evaluation by students also indicated the program was welcomed by students and that it had imparted information and skills in a context to which they could relate [36].

In summary, the final CLIMATE Schools: Alcohol Module consists of a computer-driven harm minimisation program which is based on a social influence approach. The final curriculum-based program consists of six lessons, each with two components. The first component involves students completing an interactive computer-based program, with the second consisting of a variety of individual, small group and class-based activeties. This program was designed to provide an innovative new platform for the delivery of drug education and has proven to be both feasible and effective in the school environment which is testament to this collaborative development approach.

\section{REFERENCES}

[1] McLaren, J. and Mattick, R.P. (2007) Cannabis in Australia: Use, supply, harms, and response. Prepared by National Drug and Alcohol Research Centre for the Drug 
Strategy Branch, Australian Government Department of Health and Ageing, Canberra.

[2] Copeland, J. and Swift, W. (2009) Cannabis use disorder: Epidemiology and management. International Review of Psychiatry, 21, 96-103.

[3] Botvin, G.J. (2000) Preventing drug abuse in schools: Social and competence enhancement approaches targeting individual-level etiologic factors. Addictive Behaviors, 25, 887-897. doi:10.1016/S0306-4603(00)00119-2

[4] Tobler, N.S. and Stratton, H.H. (1997) Effectiveness of School-based drug prevention programs: A meta-analysis of the research. The Journal of Primary Prevention, 18, 71-128. doi:10.1023/A:1024630205999

[5] White, D. and Pitts, M. (1998) Review: Educating young people about drugs: A systematic review. Addiction, 93, 1475-1487. doi:10.1046/j.1360-0443.1998.931014754.x

[6] Tobler, N.S., Roona, M.R., Ochshorn, P., Marshall, D.G., Streke, A.V. and Stackpole, K.M. (2000) School-based adolescent drug prevention programs: 1998 meta-analysis. Journal of Primary Prevention, 20, 275-336. doi:10.1023/A:1021314704811

[7] Foxcroft, D.R. and Tsertsvadze, A. (2011) Universal schoolbased prevention programs for alcohol misuse in young people. doi:10.1002/14651858.CD009113

[8] Dusenbury, L., Brannigan, R., Falco, M. and Hansen, W. (2003) A review of research on fidelity of implementation: Implications for drug abuse prevention in school settings. Health Education Research: Theory and Practice, 18, 237-256. doi:10.1093/her/18.2.237

[9] Ennett, S.T., Ringwalt, C.L., Thorne, J., Rohrbach, L.A., Vincus, A., Simons-Rudolph, A., et al. (2003) A comparison of current practice in school-based substance use prevention programs with meta-analysis findings. Prevention Science, 4, 1-14. doi:10.1023/A:1021777109369

[10] Hallfors, D.D. and Godette, D. (2002) Will the "princeples of effectiveness" improve prevention practice? Early findings from a diffusion study. Health Education Research: Theory and Practice, 17, 461-470. doi:10.1093/her/17.4.461

[11] Botvin, G., Baker, E., Dusenbury, L., Tortu, S. and Botvin, E. (1990) Preventing adolescent drug abuse through a multimodal cognitive-behavioral approach: Results of a 3-year study. Journal of Consulting \& Clinical Psychology, 58, 437-446. doi:10.1037/0022-006X.58.4.437

[12] Botvin, G., Griffin, K., Diaz, T. and Ifill-Williams, M. (2001) Preventing binge drinking during early adolescence: One- and two- year follow-up of a school-based preventive intervention. Psychology of Addictive Behaviors, 15, 360-365. doi:10.1037/0893-164X.15.4.360

[13] Payne, A.A., Gottfredson, D.C. and Gottfredson, G.D. (2006) School predictors of the intensity of implementation of school-based prevention programs: Results from a national study. Prevention Science, 7, 225-237. doi:10.1007/s11121-006-0029-2

[14] Dane, A.V. and Schneider, B.H. (1998) Program integrity in primary and early secondary prevention: Are implementation effects out of control. Clinical Psychology Review, 18, 23-45. doi:10.1016/S0272-7358(97)00043-3
[15] Rohrbach, L., Graham, J. and Hansen, W. (1993) Diffusion of a school-based substance abuse prevention program: Predictors of program implementation. Preventive Medicine, 22, 237-260. doi:10.1006/pmed.1993.1020

[16] Ringwalt, C., Vincus, A., Ennett, S., Johnson, R. and Rohrbach, L.A. (2004) Reasons for teachers' adaptation of substance use prevention curricula in schools with nonwhite student populations. Prevention Science, 5, 61-67. doi:10.1023/B:PREV.0000013983.87069.a0

[17] Botvin, G., Baker, E., Dusenbury, L., Botvin, E. and Diaz, T. (1995) Long-term follow-up results of a randomized drug abuse prevention trial in a white middle-class population. Journal of the American Medical Association, 273, 1106-1112. doi:10.1001/jama.1995.03520380042033

[18] McBride, N., Farringdon, F., Midford, R., Meuleners, L. and Phillips, M. (2004) Harm minimization in school drug education: Final results of the school health and alcohol harm reduction project (SHAHRP). Addiction, 99, 278-291. doi:10.1111/j.1360-0443.2003.00620.x

[19] Ringwalt, C., Ennett, S., Johnson, R., Rohrbach, L.A., Simons-Rudolph, A., Vincus, A., et al. (2003) Factors associated with fidelity to substance use prevention curriculum guides in the nation's middle schools. Health Education \& Behavior, 30, 375-391. doi:10.1177/1090198103030003010

[20] Dusenbury, L. and Falco, M. (1995) Eleven components of effective drug abuse prevention curricula. Journal of School Health, 65, 420-425. doi:10.1111/j.1746-1561.1995.tb08205.x

[21] Newman, I., Anderson, C. and Farrell, K. (1992) Role rehearsal and efficacy: Two 15 month evaluations of a ninth grade alcohol education programme. Journal of Drug Education, 22, 55-67.

[22] Dielman, T.E., Shope, J.T., Leech, S.L. and Butchart, A.T. (1989) Differential effectiveness of an Elementary Schoolbased alcohol misuse prevention programme. Journal of Drug Education, 59, 255-263. doi:10.1111/j.1746-1561.1989.tb04718.x

[23] Botvin, G., Baker, E., Botvin, E., Filazzola, A. and Millman, R. (1984) Prevention of alcohol misuse through the development of personal and social competence: A pilot study. Journal of Studies on Alcohol, 45, 550-552.

[24] Botvin, G., Epstein, J., Baker, E., Diaz, T. and Williams, M. (1997) School-based drug abuse prevention with inner-city minority youth. Journal of Child and Adolescent Substance Abuse, 6, 5-19. doi:10.1300/J029v06n01 02

[25] Griffin, K., Botvin, G., Nichols, T. and Doyle, M. (2003) Effectiveness of a universal drug abuse prevention approach for youth at high risk for substance use initiation. Preventive Medicine, 36, 1-7. doi:10.1006/pmed.2002.1133

[26] Ringwalt, C., Ennett, S.T., Vincus, A. and Simons-Rudolph, A. (2004) Students' special needs and problems as reasons for the adaptation of substance abuse prevention curricula in the nation's middle schools. Prevention Science, 5, 197-206. doi:10.1023/B:PREV.0000037642.40783.95

[27] Botvin, G., Baker, E., Filazzola, A. and Botvin, E. (1990) A cognitive-behavioral approach to substance abuse pre- 
vention: One-year follow-up. Addictive Behaviors, 15, 47-63. doi:10.1016/0306-4603(90)90006-J

[28] Shope, J., Kloska, D., Dielman, T. and Maharg, R. (1994) Longitudinal evaluations of an enhanced alcohol misuse prevention study (AMPS) curriculum for grades six-eight, Journal of School Health, 64, 160-166. doi:10.1111/j.1746-1561.1994.tb03288.x

[29] McBride, N., Farringdon, F., Muleners, L. and Midford, R. (2006) School health and alcohol harm reduction project: Details of intervention development and research procedures. W.A: National Drug Research Institute, Curtin University of Technology, Perth.

[30] Schinke, S. and Cole, K. (2003) Prevention program implementation. In: Sloboda, Z. and Bukoski W.J., Eds., Handbook of Drug Abuse Prevention: Theory, Science and Practice. Kluwer Academic/Plenum Publishers, New York, 575-587.

[31] Barber, J.G. (1990) Computer-assisted drug prevention. Journal of Substance Abuse Treatment, 7, 125-131. doi:10.1016/0740-5472(90)90008-E

[32] Gropper, M. (2002) Computer integrated drug prevention-Combining multi-media and social group work practices to teach inner city Israeli 6th graders how to say no to drugs. Journal of Technology in Human Services, 20, 49-65. doi:10.1300/J017v20n01_07

[33] Duncan, T.E., Duncan, S.C., Beauchamp, N., Wells, J. and Ary, D. (2000) Development and evaluation of an interactive CD-ROM refusal skills program to prevent youth substance use: "Refuse to use". Journal of Behavioral Medicine, 23, 59-72. doi:10.1023/A:1005420304147

[34] Schinke, S. and Schwinn, T. (2005) Gender-specific computer-based interventions for preventing drug abuse among girls. The American Journal of Drug and Alcohol Abuse, 31, 609-616. doi:10.1081/ADA-200068415

[35] Newton, N.C., Vogl, L.E., Teesson, M. and Andrews, G. (2009) CLIMATE schools: Alcohol module: Cross validation of a school-based prevention programme for alcohol misuse. Australian and New Zealand Journal of Psychiatry, 43, 201-207. doi:10.1080/00048670802653364

[36] Vogl, L., Teesson, M., Andrews, G., Bird, K., Steadman, B. and Dillon, P. (2009) A computerized harm minimization prevention program for alcohol misuse and related harms: Randomized controlled trial. Addiction, 104, 564575. doi:10.1111/j.1360-0443.2009.02510.x

[37] Cahill, H. (2006) Devising classroom drug education programs. In: Midford, R. and Munro, G., Eds., Drug Education in Schools: Searching for the Silver Bullet. IP Communications, Melbourne.

[38] Kaftarian, S., Robinson, E., Compton, W., Davis, B.W. and Valkow, N. (2004) Blending prevention research and practice in schools: Critical issues and suggestions. Prevention Science, 5, 1-3. doi:10.1023/B:PREV.0000013975.74774.bc

[39] Meyer, L. and Cahill, H. (2004) Principles for school drug education. Australian Government Department of Education Science and Training, Canberra.

[40] Faden, V.B. (2006) Epidemiology. In: Galanter, M., Ed., Alcohol Problems in Adolescence and Young Adults.
Springer, New York.

[41] Moskowitz, J.M. (1989) The primary prevention of alcohol problems: A critical review of the research literature. Journal of Studies on Alcohol, 50, 54-88.

[42] Midford, R., Munro, G., McBride, N., Snow, P. and Ladzinski, U. (2002) Principles that underpin effective schoolbased drug education. Journal of Drug Education, 32, 363-386. doi:10.2190/T66J-YDBX-J256-J8T9

[43] Ministerial Council on Drug Strategy (2006) National alcohol strategy 2006-2009: Towards safer drinking cultures. The Australian Government, Canberra.

[44] Midford, R., McBride, N. and Munro, G. (1998) Harm reduction in school drug education: Developing an Australian approach. Drug \& Alcohol Review, 17, 319-327. doi:10.1080/09595239800187151

[45] Hawks, D., Scott, K. and McBride, N. (2002) Prevention of psychoactive substance use: A selected review of what works in the area of prevention. World Health Organization Mental Health: Evidence and Research Department of Mental Health and Substance Dependence, Geneva.

[46] McBride, N. (2003) A systematic review of school drug education. Health Education Research, 18, 729-742. doi:10.1093/her/cyf050

[47] Berkowitz, M.W. and Begun, A. (2003) Designing prevention programs: The developmental perspective. In: Sloboda, Z. and Bukoski, W.J., Eds., Handbook of Drug Abuse Prevention: Theory, Science and Practice. Kluwer Academic/Plenum Publishers, New York, 327-348.

[48] Roberts, G., McCall, D., Stevens, L.A., Anderson, J., Paglia, A., Bollenbach. S., et al. (2001) Preventing substance use problems among young people: A compendium of best practices. Office of Canada’s Drug Strategy, Health Canada, Ottawa.

[49] Marlatt, G. (1996) Harm reduction: Come as you are. Addictive Behaviors, 21, 779-788. doi:10.1016/0306-4603(96)00042-1

[50] National Health and Medical Research Council (2009) Australian guidelines: To reduce health risks from drinking alcohol. NHMRC, Canberra.

[51] National Health and Medical Research Council (2001) Australian alcohol guidelines: Health risks and benefits. NHMRC, Canberra.

[52] Dusenbury, L. and Falco, M. (1997) School-based drug abuse prevention strategies. In: Weissberg, R., Gullotta, T., Hampton, R., Ryan, B. and Adams, G., Eds., Enhancing Children's Wellness. SAGE Publications, Thousand Oaks.

[53] Schinke, S., Schwinn, T., Di Noia, J. and Cole, K. (2004) Reducing the risks of alcohol use among urban youth: Three-year effects of a computer-based intervention with and without parent involvement. Journal of Studies on Alcohol, 65, 443-449.

[54] Gregor, M.A., Shope, J.T., Blow, F.C., Maio, R.F., Weber, J.E. and Nypaver, M.M. (2003) Feasibility of using an interactive laptop program in the emergency department to prevent alcohol misuse among adolescents. Annals of Emergency Medicine, 42, 276-284. doi:10.1067/mem.2003.265 
[55] White, V. and Hayman, J. (2006) Australian secondary school students' use of alcohol in 2005. Australian Government Department of Health and Ageing, Canberra.

[56] Maggs, J. and Schulenberg, J. (1998) Reasons to drink and not to drink: Altering trajectories of drinking through an alcohol misuse prevention program. Applied Developmental Science, 2, 48-60. doi:10.1207/s1532480xads0201 4

[57] Shope, J., Elliot, M., Raghunathan, T. and Waller, P. (2001) Long-term follow-up of a high school alcohol misuse prevention program's effect on students subsequent driving. Alcoholism: Clinical and Experimental Research, 25, 403410.

[58] Commonwealth Department of Education Science and Training (2003) REDI for School Communities: A resilience approach to drug education. Commonwealth Department of Education Science and Training, Canberra.

[59] Botvin, G. (2000) Life skills training: middle school program. Princeton Health Press, Inc., Princeton.

[60] Sussman, S., Craig, S. and Moss, M.A. (2001) Project T.N.D: Project towards no drug use: Teachers manual. Los Angeles.
[61] National Drug Research Institute (2000) School health and alcohol harm reduction project (SHAHRP). 3rd Edition, NDRI, Canberra.

[62] Commonwealth Department of Education Science and Training (2003) Cannabis and consequences. Commonwealth Department of Education Science and Training, Canberra.

[63] Youth Research Centre (1995) Rethinking drinking you're in control. University of Melbourne, Melbourne.

[64] McAllister, I. (2003) Alcohol consumption among adolescents and young adults. Australian National University, Canberra.

[65] Hansen, W. and Graham, J. (1991) Preventing alcohol, marijuana, and cigarette use among adolescents: Peer pressure resistance training versus establishing conservative norms. Preventive Medicine, 20, 414-430. doi:10.1016/0091-7435(91)90039-7

[66] Midford, R. (2006) The Dame Elizabeth oration: Is Australia "fair dinkum" about drug education schools? The 5th International Conference on Drugs and Young People, Sydney, 24 May 2006. 